\title{
Production of Biogas from Fruit and Vegetable Wastes Mixed with Different Wastes
}

\author{
Leta Deressa $^{1}$, Solomon Libsu ${ }^{2}$, R. B. Chavan ${ }^{3}$, Daniel Manaye ${ }^{1}$, Anbessa Dabassa ${ }^{4, *}$ \\ ${ }^{1}$ Department of Chemistry, Faculty of Natural and Computational Sciences, Mettu University, Ethiopia \\ ${ }^{2}$ Department of Chemistry, College of Natural and Computational Sciences, Bahir Dar University, Ethiopia \\ ${ }^{3}$ Department of Textile, College of Engineering, Bahir Dar University, Ethiopia \\ ${ }^{4}$ Department of Biology, Natural Science College, Jimma University, Ethiopia
}

Copyright (C) 2015 Horizon Research Publishing All rights reserved.

\begin{abstract}
The present work explores the production of biogas from fruit and vegetable wastes mixed with cow manure in an anaerobic digester. The total solid, volatile solids, moisture content and ash content of the wastes were examined. The materials used as feed were avocado, papaya, mango, tomato, banana peel, and cow manure. Varying volumes of digesters were employed for biogas generation. The combustibility of the gas so generated was tested. The anaerobic digestion of fruit and vegetable wastes mixed with different waste took 55 days to produce biogas (for complete digestion). Anaerobic digestion is very sensitive to change in $\mathrm{pH}$ and it is important to maintain $\mathrm{pH}$ of 6.7-7.4 for healthy system. The temperature of the digester and the environment also affects the anaerobic digestion process. Upon adjustment of the factors affecting anaerobic digestion, it is felt that co-digestion between FVW and CM produces biogas without need of nutrient or chemical addition to the system. The search for alternative source of energy such as biogas should be intensified so that ecological disasters like environmental pollution, deforestation, desertification and erosion can be arrested.
\end{abstract}

Keywords Anaerobic Digestion, Fruit and Vegetable Wastes, Co-Digestion, Fertilizer, Biogas

\section{Introduction}

In today's fast-growing world, the rate of energy consumption is rising at unexpected rates with each passing day. Ethiopia has also part of this global trend particularly over the last decade. To meet its growing energy requirements, the country has been investing hugely in developing its hydroelectric power generating capacity from water source like Gelgel Gibe dam, Abay River dam, Fincha dam and the like. Besides, the country also relies substantially on the fuel it imports to meet its energy demand.

Development of renewable and sustainable energy source is the best solution to the country's energy demands [1]. It is much desirable that the renewable energy to be developed has no adverse effects on the environment. Surely, productions of renewable energy from materials that are readily and locally available are extremely advantageous and reduce the cost of its production. Environmentally friendly individuals may choose to compost their food waste to acquire a useful fertilizer or soil amendment; however, this process does not allow a means to capture the energy that is locked up in waste. Many municipal waste management programs do attempt to harness organic waste energy through combustion in waste-to-energy plants and methane collection from microorganism activity in landfills. While such systems make use of the energy available in food waste, they do not directly benefit the individuals who produce the waste, and may also involve additional costs to those individuals related to collection [2].

Biogas-generating technology is a favorable dual-purpose technology at present: the biogas generated can be used to meet energy requirements while the organic residue is a useful fertilizer. Biogas is a type of renewable energy that can be produced from the decomposition of animal and plant wastes and is composed of methane, carbon dioxide and trace impurities like hydrogen, hydrogen sulfide and some nitrogen [3].

The production of methane during the anaerobic digestion of biologically degradable organic matter depends on the amount and kind of the material added to the system. So, leftover foods, fruit and vegetable wastes and cow manure may be subjected to anaerobic digestion for energy production in a variety of ways. The leading concepts now-a-days are: single-phase digestion, two phase digestion, dry fermentation and co-digestion [4].An interesting option for improving yields of anaerobic digestion of wastes are co-digestion, which employs a co- substrate that has the benefit of improving the biogas yields due to positive 
synergism established in the digestion medium and the supply of missing nutrients for microorganisms [5]. So, using co-digestion of leftover foods, fruit and vegetable wastes and cow manure is an alternative way to improve biogas technology. The reactor used in this type of system would almost certainly need to be operated at mesophilic temperatures (between $25^{\circ} \mathrm{C}$ and $40^{\circ} \mathrm{C}$ ) to minimize heating costs. Even if the methane yield was better under thermophilic conditions (between $55^{\circ} \mathrm{C}$ and $60^{\circ} \mathrm{C}$ ), it would very likely not be enough to offset the cost of maintaining the reactors $15^{\circ}$ to $30^{\circ}$ hotter.

This study aims at the production of biogas from biologically degradable wastes by co-digestion system. Various ratios of mixed wastes were prepared to feed the biogas digester.

\section{Materials and Methods}

In this work, various types of fruit and vegetable wastes (FVW), leftover foods from students' cafeteria of Bahir Dar University mixed with cow manure (CM) are used as substrates for biogas production in two 80Littres cylindrical plastic anaerobic digesters and two 2 Littres plastic bottles. In the above stated biogas digester one of the cylindrical plastic anaerobic digester and one of the plastic bottles prepared for leftover foods of students' cafeteria and cow manure and the left two prepared for fruit and vegetable wastes mixed with cow manure.

\subsection{Construction of the Anaerobic Digesters}

\subsubsection{Construction of Anaerobic Digester for Semi Continuous System}

The anaerobic plastic digester, shown in (Fig. 1), has the following dimensions: $42 \mathrm{~cm}$ diameter on the cover of the mouth of the container, $36 \mathrm{~cm}$ diameter at the bottom and a height of $95 \mathrm{~cm}$. Three holes were made on the container. Two of these had a diameter of $3.75 \mathrm{~cm}$ each. One of these, made on a tightly sealed cover of the digester, was connected with a bucket containing the slurry and served as inlet for the feed while the other opening, made at the bottom of the container, served as outlet for the digested waste. The third opening with of diameter $1.25 \mathrm{~cm}$ and connected to a gas burner, served as outlet for the biogas generated. The openings for feed inlet and outlet of digested waste were located below the opening of the outlet for biogas in order to prevent the leakage of biogas to the ambient air.

\subsubsection{Construction of Anaerobic Digester for Batch System}

The anaerobic biogas generation from fruit and vegetable wastes mixed with cow manure was also attempted using a smaller (20L) plastic container with dimensions of diameter $24 \mathrm{~cm}$ on each end and a height of $30 \mathrm{~cm}$. The digester, shown in (Fig 2), had two openings. One of these, $5 \mathrm{~cm}$ in diameter, served as inlet for the feed. The second opening, $1.25 \mathrm{~cm}$ in diameter, was connected to a Bunsen burner through a rubber tube and served as outlet for the gas generated. Both the openings were made air tight throughout the digestion process.

A third group of four digesters(Fig. 3), consisted of plastic bottles of $3 \mathrm{~cm}$ and $9 \mathrm{~cm}$ diameter, respectively, the mouth and the bottom and a height of $35 \mathrm{~cm}$. The total volume of each of these digesters is 1.8 liter. A rubber tube connected to each of these digesters through the mouth of the bottle served as an outlet for the gas generated.

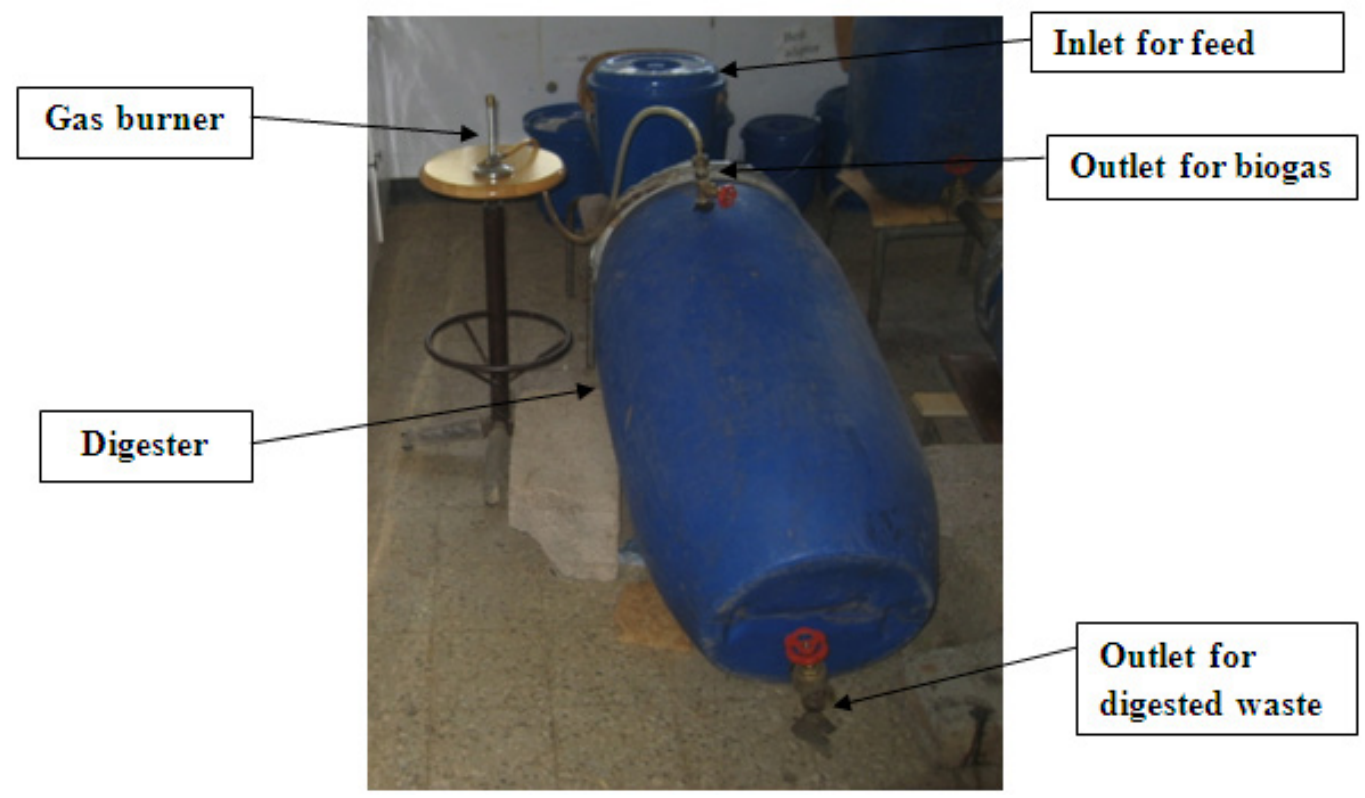

Figure 1. Plastic anaerobic digester 


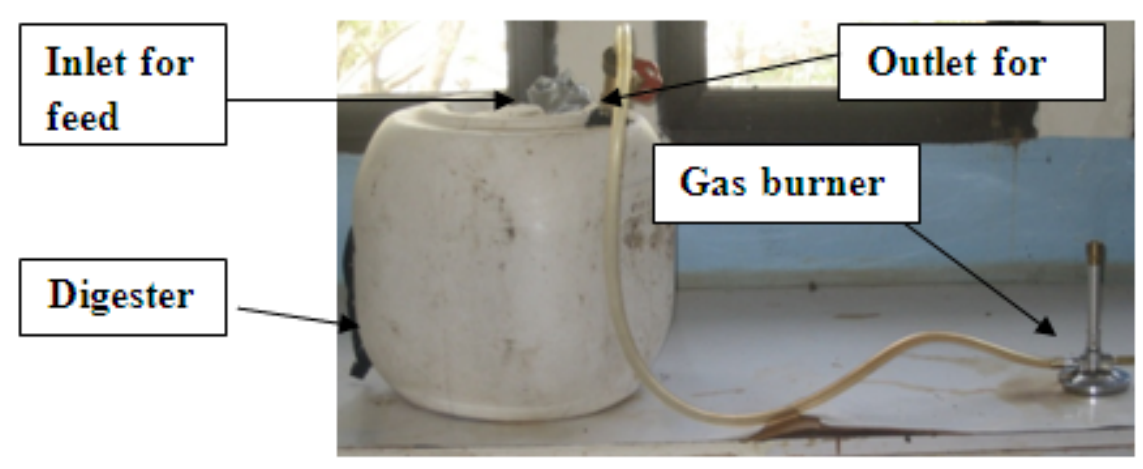

Figure 2. Pilot scale anaerobic digester of $20 \mathrm{~L}$ capacity

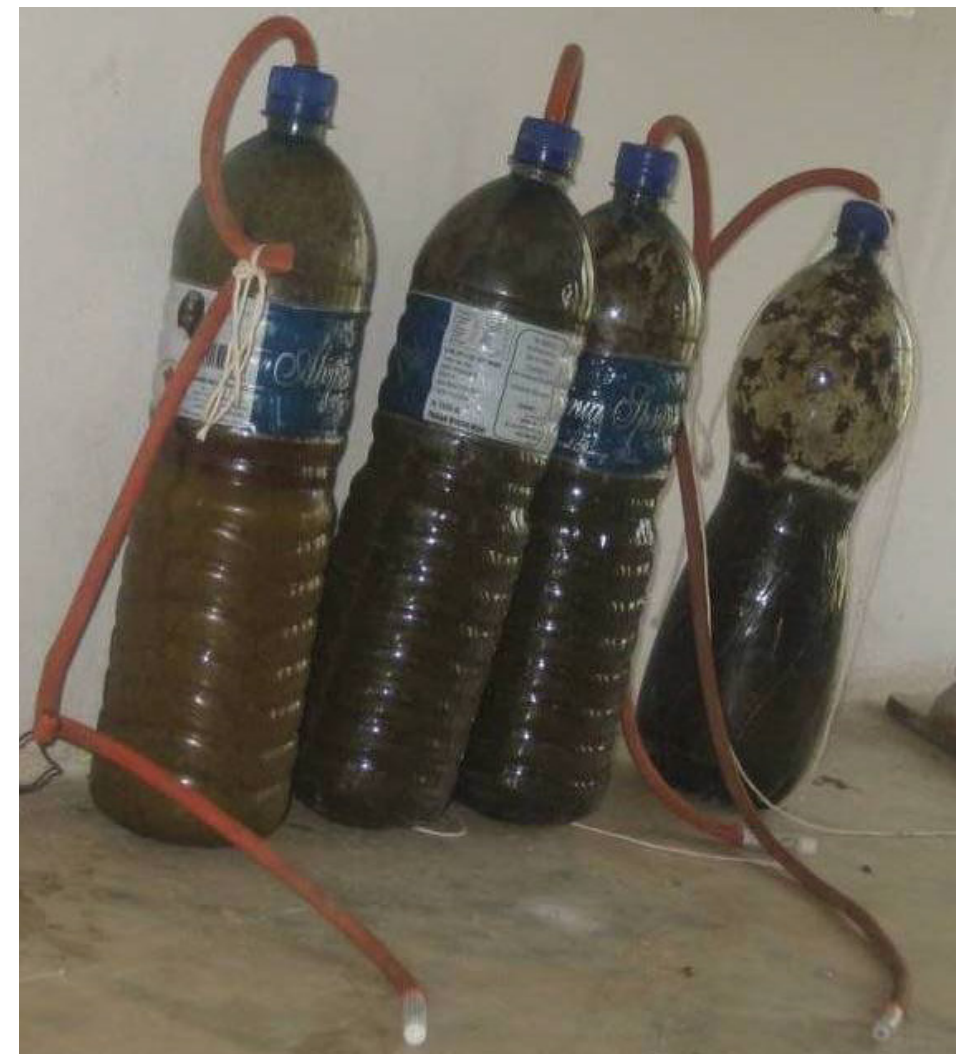

Figure 3. Pilot scale anaerobic digesters of $1.8 \mathrm{~L}$ volume

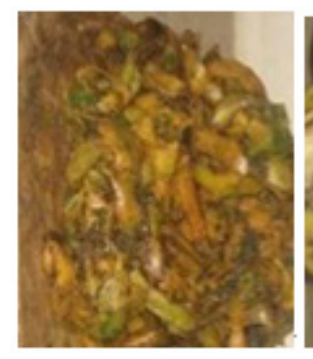

Mango

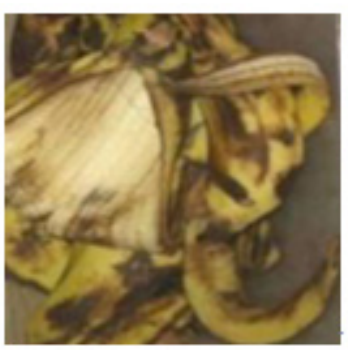

banana peel

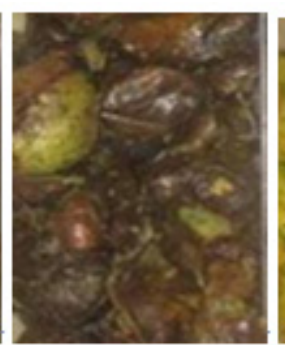

avocado

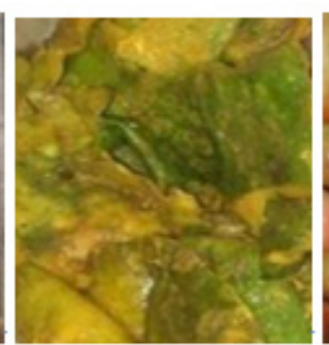

papaya

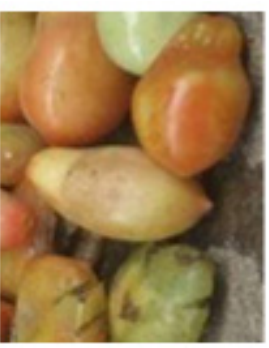

Tomato

Figure 4. Fruit and vegetable wastes used for the present study 


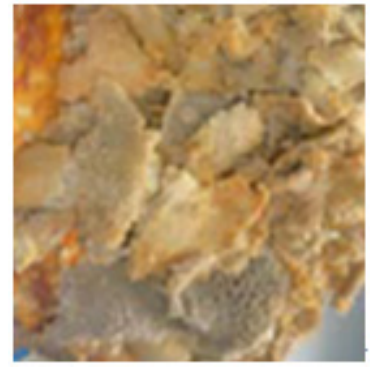

Mixed leftover foods

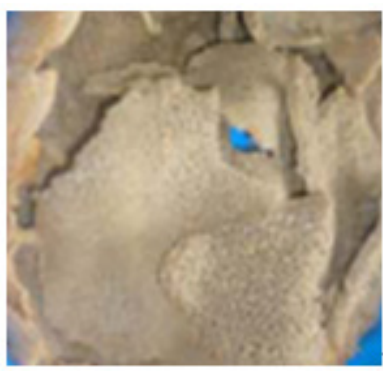

Leftover of injera

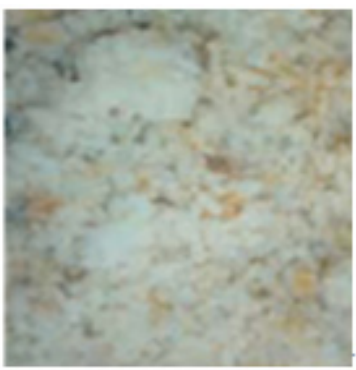

Cooked rice

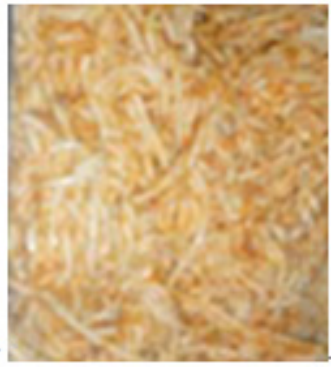

Cooked pasta with silse

Figure 5. Some of Leftover foods for the present study

\subsection{Substrate Collection}

\subsubsection{Fruits and Vegetable Wastes (FVW)}

FVW for the present study were collected from juice shops located in Mettu town. The wastes, a portion (Fig.4), were hand-picked and utmost care was taken to include all varieties of fruits used in the Mettu town.

\subsubsection{Leftover foods}

Leftover foods for the present study were collected from Bahir Dar university students' cafeteria and some of some of the leftover foods used were presented in fig 5. The leftover food contains injera, pasta, kinche and mokoroni mixed with shiro and misir watt.

\subsubsection{Cow manure}

Cow manure used in the present study, a sample of which is shown in (Fig. 6), was collected from Bahir Dar University's ranch in the Main Campus. The cow manure collected was not more than one day old.

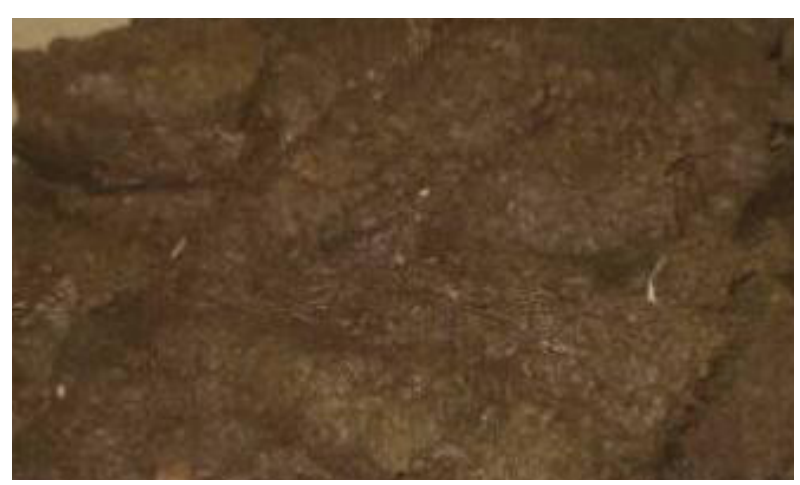

Figure 6. Sample of Cow manure used for present study

\subsection{Sample Preparation}

Fruit and vegetable wastes were collected from juice shops in Bahir Dar town. Plastic materials, other food items such as bones, non-digestible materials were carefully separated from the substrate. The mixture of biodegradable used in this work comprises peels of avocado, papaya, mango, tomato, banana, bread, injera, noodle and cooked rice. The proportion and type of FVW and leftover foods used for biogas generation presents Table 1 .
Table 1. Composite of biomass used for the present study for production of biogas

\begin{tabular}{|c|c|}
\hline Name of wastes & Weight in percent \\
\hline Cow dung & 13 \\
\hline Avocado & 5.4 \\
\hline Papaya & 8 \\
\hline Mango & 6 \\
\hline Tomato & 7.5 \\
\hline Banana peel & 4.8 \\
\hline Bread & 5.1 \\
\hline Injera & 8.2 \\
\hline Noodle & 5 \\
\hline Cooked rice & 4.5 \\
\hline Mixed leftover foods & 32.5 \\
\hline Total & 100 \\
\hline
\end{tabular}

Following collection of the biodegradable organic waste, the wastes were prepared for feedstock by chopping manually to a size of 1-4 mm"; "the characteristics of of the wastes were determined.

\subsubsection{Preparation of Mixed Wastes}

Slurry of approximately $5 \mathrm{Kg}$ of the mixed waste (consisting of $50 \%$ each of FVW and cow manure and leftover foods mixed with cow manure) and $50 \%$ of leftover food stuffs in another digester, in about 1:5 of tap water was fed into the digester. The FVW and leftover food stuffs portion of the mixed waste fed into the digester consisted of wet weights of waste as indicated in Table 1 . The volatile solids of the mixed wastes were calculated using Equation 2.

\subsection{Experimental}

\subsubsection{Start-up}

Slurry obtained by mixing fresh cow manure and tap water in a 1:5 ratio by weight was used for start-up of the digestion for two days.

\subsubsection{Feeding and Operating to Steady State}

Before feeding into digester, the slurry was mixed by hand in a separate container for few minutes and fed to the digester daily for five days. After feeding the mixed waste into the 
digester the mouse of the digesters were closed. The organic loading rate (OLR) under the 30 operation condition, determined using a reported method, was found to be approximately $0.62 \mathrm{Kg}$ of $\mathrm{VS} / \mathrm{m}^{3}$ of digester. About $75 \%$ of the digester volume was filled with the slurry.

\subsubsection{Data Collecting and Analysis Method}

The physical characteristics (total solids; volatile solids; moisture content and ash content) were analyzed by a standard method for the examination of water and waste water [6].The temperature and the $\mathrm{pH}$ in each digester were measured at the start. The slurry was sampled at start-up and end of the digestion for the total solids (TS), volatile solids (VS), ash content and moisture content determination.

\subsubsection{Physico-chemical analyses}

The $\mathrm{pH}$ of digester liquid, influent and effluent, temperature of gas production volume were monitored. In addition to this, TS and VS of the manure after digestion were determined. The TS/VS lost in fermenter and efficiencies of VS conversion to gas was also monitored at the end of the study. These parameters were determined in accordance with APHA.

\subsubsection{Total solids (TS)}

Total solids denote organic as well as inorganic matter in the feedstock [7].TS were measured according to APHA [6].A $20 \mathrm{~g}$ of fresh feedstock was weighed (W2) in an empty crucible (W1) and dried in an oven maintained at $105^{\circ} \mathrm{C}$ for 24 hour (W3). Per cent TS was calculated by using Equation 1 as shown below.

$$
\% T S=\frac{W_{3}-W_{1}}{W_{2}} \times 100
$$

\subsubsection{Volatile solids (VS)}

Volatile solids represent organic matter of the feedstock (excluding the inorganic salts, ash). This, too, was measured in accordance with APHA [6].A 3g of oven dried sample was weighed (B) in an empty crucible (A) and heated to $550^{\circ} \mathrm{C}$ for 1 hour in the muffle furnace to constant weight (C). Per cent VS was calculated by using Equation 2[8].

$$
\% V S=\frac{C-A}{B} \times 100
$$

\subsection{Indicators of Efficiency}

The performance of the reactor and conversion efficiency of feedstock is estimated from the following indicators:

\subsubsection{TS/VS Lost}

Initial TS/VS of the feedstock was determined before feeding into the reactor. After destructive sampling, the final TS/VS were determined. The difference between the initial (mass of TS/VS fed) and final TS/VS (residual TS/VS in the digested feedstock) gave the quantity of TS/VS lost. The arithmetic is done by using Equation 3 .

$$
\frac{T S}{V S} \text { lost }=\text { initial } \frac{T S}{V S}-\text { final } \frac{T S}{V S}
$$

\subsubsection{TS/VS to Gas}

The TS/VS lost was determined after destructive sampling as mentioned above. It was presented as liters of biogas produced per gram TS/VS lost. This gave an index of process efficiency.

\subsubsection{Expected Gas Production Level from TS and VS Lost}

A mass balance approach was used to estimate the theoretical gas yield from the TS/VS lost. The volume of the biogas produced was assumed to be equivalent to the amount of VS lost during the process. The difference between the observed and the theoretical yield of biogas gave the TS/VS lost due to unbalanced ratio of microorganism to substrate, process inefficiency (such as, conversion proceed till the formation of VFA not further to gas) and physical leakage, or the other factors.

\section{Result and Discussion}

\subsection{Composition and Characteristics of the Wastes}

The presented data on the moisture content, total solid, volatile solid and ash content of the wastes used for the study presents Table 2. From the table it is evident that tomato had maximum moisture content of $83.15 \%$ and breads the least with a moisture content of $55.82 \%$. The maximum TS were recorded in bread (44.18\%). The VS in all wastes used for the study varied from $91.24 \%$ (avocado) to $96.14 \%$ (mixed wastes). The results obtained from the present work for individual wastes are comparable with values reported by Mital [9]. Viswanath has reported that banana and tomato contain $29.5 \%$ and $11.8 \%$ TS, respectively [10]. These results are comparable with values recorded presently. Working on food processing wastes including peels of mango, tomato, lemon, orange and pineapple, Nand has reported that the TS content in them varied from $28.4 \%$ to 23.4\% [11]. The values for VS obtained presently are also comparable to $92.73 \%$ reported by Nand for rotten fruits and vegetable wastes. The percent of high moisture content in the organic waste facilitates the anaerobic digestion [12]. 
Table 2. Characteristics of wastes used for feed

\begin{tabular}{|c|c|c|c|c|c|c|c|}
\hline $\begin{array}{c}\text { Sl. } \\
\text { No }\end{array}$ & Name of wastes & $\begin{array}{c}\text { Weight } \\
(\mathrm{g})\end{array}$ & $\begin{array}{c}\text { Moisture } \\
\text { content }(\%)\end{array}$ & $\begin{array}{c}\text { Total solid } \\
(\%)\end{array}$ & $\begin{array}{c}\text { Volatile solid } \\
(\%)\end{array}$ & Ash content (\%) & $\begin{array}{c}\text { TS/VS } \\
(\%)\end{array}$ \\
\hline 1 & Mango & 6 & 83.6 & 16.4 & 94.8 & 5.2 & 0.17 \\
\hline 2 & Avocado & 5.4 & 73.2 & 26.8 & 91.24 & 8.76 & 0.29 \\
\hline 3 & Papaya & 8 & 78.65 & 21.35 & 92.12 & 7.88 & 0.23 \\
\hline 4 & Tomato & 7.5 & 83.14 & 16.86 & 92.85 & 7.15 & 0.18 \\
\hline 5 & Banana peel & 4.8 & 81 & 19 & 92.6 & 7.4 & 0.21 \\
\hline 6 & Bread & 5.1 & 44.18 & 55.82 & 92.08 & 7.82 & 0.61 \\
\hline 7 & Injera & 8.2 & 60.57 & 39.43 & 93.78 & 6.22 & 0.42 \\
\hline 8 & Cooked pasta & 5 & 76.88 & 23.12 & 92.81 & 7.19 & 0.25 \\
\hline 9 & $\begin{array}{c}\text { Mixed leftover } \\
\text { foods }\end{array}$ & 32.5 & 64.66 & 35.34 & 96.14 & 3.96 & 0.37 \\
\hline 10 & Cooked rice & 4.5 & 67.95 & 32.05 & 93.2 & 6.8 & 0.34 \\
\hline 11 & Cow dung & 13 & 79.75 & 20.25 & 91.56 & 8.44 & 0.22 \\
\hline
\end{tabular}

The characteristics of cow manure studied in this paper are as follows: the TS $20.25 \%$ of wet weight, VS $91.56 \%$, ash content $8.44 \%$ and moisture content of $79.75 \%$. Some characteristics of $\mathrm{CM}$ reported by different researchers include: $16 \%$ TS by Somachi [13], 77\% moisture content by Nusara [14], 9.3\% TS and 80.3\% VS by Chongrak [15].The present study also agrees with the values reported by these researchers.

The mixed wastes of FVW and CM consisted of 75:25 in ratio respectively. The characteristics of these wastes were found to be: TS $20.65 \%$ of wet weight, VS $96 \%$, ash content $4 \%$ and moisture content of $79.35 \%$. The mixed wastes of leftover food of students cafeteria mixed with $\mathrm{CM}$ consisted of 75:25 ratio. The characteristics of these wastes were found to be TS $35.34 \%$ of wet weight, VS $96.14 \%$, ash content $3.88 \%$ and moisture content of $79.35 \%$.

The $\mathrm{pH}$ of mixed wastes in each digester ranged from 6 to 7.2 which are comparable with the optimum range of $\mathrm{pH}$ for production of biogas [16]. This result showed that the microorganisms in the anaerobic digesters were not affected by the $\mathrm{pH}$ of the slurry in the digester. Therefore, no inhibition of biogas production from wastes mixed with cow manure due to effect of $\mathrm{pH}$. The temperature in all digesters ranged from 26 to $32^{\circ} \mathrm{C}$ which happens to be in the range of mesophilic, $25-45^{\circ} \mathrm{C}$ which is allowed for production of biogas.

\subsection{The Efficiencies of Total Solids and Volatile Solids Reduction}

Table 3. Efficiency of Total Solids and Volatile Solids Reduction

\begin{tabular}{|c|c|c|c|c|c|c|}
\hline \multirow{2}{*}{ Component } & \multicolumn{3}{|c|}{ Food waste +cow manure } & \multicolumn{3}{c|}{ FVW+ cow manure } \\
\cline { 2 - 7 } & initial & Final & reduction & initial & final & reduction \\
\hline TS & 35.34 & 17.53 & 17.81 & 20.65 & 9.96 & 10.69 \\
\hline VS & 96.14 & 54.8 & 41.34 & 96 & 56 & 40 \\
\hline TS/VS & 0.367 & 0.32 & 0.047 & 0.215 & 0.178 & 0.037 \\
\hline
\end{tabular}

The steady state of anaerobic digesters in this investigation occurs after 15 days of the start- up process. During the steady state, the reduction efficiencies of averages of total solids (TS) and volatile solids (VS) for food wastes mixed with cow manure (17.81 and 54.85 respectively) and for FVW mixed with CM (9.96 and 56 respectively). This indicates that the mixed wastes are converted to biogas thus necessitating addition of further substrate into the digester. The initial TS/VS of the mixed waste of fruit and vegetable waste mixed with cow manure were 0.215 . After the anaerobic digestion of the mixed waste, the final TS/VS of the residue waste dropped to 0.178 . The difference between the initial mass of TS/VS residue was 0.037 . The initial TS/VS of the mixed waste of leftover foods mixed with cow manure were 0.367 . After the anaerobic digestion of the mixed waste, the final TS/VS of the residue waste dropped to 0.32 . The difference between the initial mass of TS/VS residue was 0.047 (Table 3).

\subsection{Biogas Production}

Biogas generation in all the digesters constructed was evident. Pressure build-up in the empty space of each digester was noted after 15 days of start up. Combustibility of the biogas generated in the larger digesters was tested using a Bunsen burner that was connected to the gas outlet through a rubber tube. A sustained flame was expected from combustion of the gas, however, not observed.

In the smaller digester (plastic bottles of 2L), biogas gas generation was started after few days of start-up. The total volume of gas so generated is not measured due to lack of instrument. The biogas is expressed according to the ratio of TS/VS lost from leftover food waste of students cafeteria mixed with cow manure is $0.0471 / \mathrm{g}(47 \mathrm{ml} / \mathrm{g})$. The biogas produced from Fruit and vegetable wastes mixed with cow manure is $0.0371 / \mathrm{g}(37 \mathrm{ml} / \mathrm{g})$. By water displacement method the biogas produced from leftover food waste of students cafeteria mixed with cow manure is $0.042 \mathrm{ml} / \mathrm{g}(42 \mathrm{ml} / \mathrm{g})$. The biogas produced from Fruit and vegetable wastes mixed with cow manure is $0.031 \mathrm{ml} / \mathrm{g}(31 \mathrm{ml} / \mathrm{g})$. The difference of biogas 
measured by ratio of TS/VS and displacement method tell us leakage of gas by different methods. From measured value it is evident that leftover food waste of students cafeteria mixed with cow manure will give more biogas than Fruit and vegetable wastes mixed with cow manure.

The incombustibility of the biogas produced in larger digesters may be due to:

- Insufficient number of methanogenic bacteria that convert acetic acid and carbon dioxide to methane.

- The settlement of solids or accumulation of digested solids at the bottom of the digester that allow scum formation at the slurry surface.

- Unavailability of contact between the microorganisms and substrates.

- The starting season in which the digester constructed, the temperature of the environment has been decreased and also changed from mesophilic range. Due to this the generation of the gas will be decreased and finally inhibited.

\section{Conclusions}

It is observed from reduction of TS/VS that production of biogas from leftover food waste of students cafeteria mixed with cow manure will give more biogas than Fruit and vegetable wastes mixed with cow manure. The process of biogas production is not merely source of energy, but also used as source of organic fertilizer.

Biogas production process is microbial in nature is affected by temperature, $\mathrm{pH}$, volatile fatty acids, microbial population and ammonia. The control of these factors determines the quality and quantity of biogas produced. Production of biogas from food waste is a major step toward harnessing one of the world's most prevalent, yet least utilized renewable energy resource.

As the world's population grows and pressure on finite resources increases, we all have a responsibility to adopt the way "reuse, reduce and recycle" when it comes to resources and waste. In Mettu University, some food waste is always inevitable but the massive environmental damage caused by dumping waste food in landfill is not. Through the use of green technologies like anaerobic digestion, can avoid the emission of harmful greenhouse gasses and make a positive contribution to environmental targets.

\section{Conflict of Interests}

All authors have no conflict of interests concerning the work reported in this paper.

\section{Acknowledgements}

First of all we would like to thank the charity God who gave us all what we need and guided us to be successful in our aim. We were greateful to Bahir Dar university, for financial and material support.

Lastly but not the least our grate thank from the bottom of our heart go to peoples who helped us in collecting data, constructing biogas digester, analysing and characterizing samples.

\section{REFERENCES}

[1] Donald, L. Biomass for Renewable Energy, Fuels and Chemicals; Academic Press. 1998; p 445-491.

[2] Lohri, C. Research on anaerobic digestion of organic solid waste at household level in Dares Salaam, Tanzania; Bachelor Thesis at ZHAW (Zurich University of Applied Sciences) in collaboration with Eawag (Swiss Federal Institute of Aquatic Science andTechnology). 2009.

[3] Heb, F. Decentralised Anaerobic Digestion of Market Waste - A Case Study inThiruvananthapuram, India. Sandec Report. 2009.

[4] Chanakya, H.N.; Ramachandra, T.V.; Vijagachamundeeswari, M. Anaerobic digestion and reuse of digested products of selected products of urban solid waste, 2006.

[5] Rungvichaniwat J. Msc Thesis. Mahidol University, 2003.

[6] APHA. Standard Methods for the Examination of Water and Wastewater. 20th edition. Washington, D.C, USA. 1998.

[7] Adams, I, U.; Happiness I, U. J. Am. sci. 2010, 6, 173-178.

[8] Fernandez, B.; Porrier, P.; R. Chamy. Water. Sci. Technol. 2001, 44, 103-108.

[9] Mital, K. M.; Biogas system principles and applications. Newage International Private Limited, New Delhi, India. 1996.

[10] Viswanath, P.; Perma, S.; Sumithra, D.; Nand, K. Biores. Technol. 1992, 40, 43-48.

[11] Nand, K. Indian Food Industry. 1994, 3, $23-24$.

[12] Boullagui, H.; Cheilch, H, B.; Marouani,L.; Hamdi, M. J. Biores. Technol. 2003, 86, 85-89.

[13] Nusara, W. J. Environ. Sci. 2007, 19, 1025-1027.

[14] Graunke, R. Food and Fuel; Biogas Potential at Broward Dinig Hall, Soil and Water Science Department University of Florida-IFAS. 2007.

[15] Chua, K. H.; Yip, C.H and Nie, W. L. S. A Case Study on the Anaerobic Treatment of Food Waste and Gas Formation. 2008. 